simpler methods as distinct from 'modern' methods of preservation will be needed. Research is therefore needed to try to make 'traditional' methods such as drying, smoking, salting, and fermentation more trustworthy and effective. The programme also envisages work on fish flour and on use of antibiotics in food preservation, especially in regions with high ambient temperatures. In relation to the use of wild or semi-wild herbivores for meat production the main problem is that the source putrefies and becomes dangerous in something like $6 \mathrm{~h}$ if it is not cut up and cooled. There is a certain amount of evidence that injection of antibiotics could be useful in controlling this situation; one or two investigations under tropical conditions have been made, but none have paid attention to the behaviour of anaerobic bacteria which are the important ones in this situation.

\title{
Animal nutrition in the Use and Management Programme
}

\section{By A. T. Phillipson, Department of Veterinary Clinical Studies, University of Cambridge}

In discussing the International Biological Programme (IBP) and aspirations in relation to the nutrition of animals, I shall regard 'nutrition' in a broad way. The subject matter so far included in the IBP that can be considered as strictly nutritional in relation to animals is so far very small. Indeed, the kinds of problem with which IBP is concerned mean that nutrition is only a part of a problem that involves all its allied sciences.

It has been emphasized that all sections of IBP are to some extent concerned with food production. If the activities of IBP make a material contribution to the food problems of the world, it will undoubtedly have served a useful purpose. The Use and Management (UM) Programme as far as animal nutrition is concerned, has a strong emphasis on exploring various ways of increasing the world's supply of animal products. Fortunately, mankind's predatory habits do not always outweigh his interest in animals and the biological environment in which they live, so that it is clearly understood that exploitation of unusual and possible sources of animal protein can only be successful if a thorough study is made of the ecological situation in which animals live as well as the characters of individual species within a population. The preservation of wild animal communities on account of their intrinsic value for biological study is not, strictly speaking, part of the activity of section UM but of section CT (Conservation of Terrestrial Communities). Even so, section UM and section PT (Productivity of Terrestrial Communities) who have joined forces on a comparative study of wild and tame herbivores are acutely aware of the need to understand the existing balance between wild herbivores and their environment if they are to come to any conclusion on the possibilities of future exploitation.

It was to explore the need for information on these matters that a symposium was organized at Aberdeen and Cambridge in the autumn of $x_{9} 65$ under the auspices of 
Sections PT and UM. Specialists from nineteen countries were invited and the purpose of the symposium was 'to advise on the best methods of studying the ecology and physiology of large wild and tame herbivores in the main biogeographic regions, in relation to long term biological production'.

The breadth of the subjects discussed at this symposium is illustrated by the first session in which papers were given on 'the carrying capacity of ecosystems', 'the importance of studying energy production and transfer', 'the need to establish base-lines by experiments on captive animals', 'what is feasible in physiology?' 'problems of studying reproduction in ungulates' and 'the study of epizootiology of infectious diseases in wild animals'. After this introductory session, the symposium divided into sections to discuss different methods that would be of general use in field work. These discussions were concerned with: (I) carrying capacity of ecosystems; (2) population ecology; (3) nutrition and physiology; (4) reproduction and growth; (5) the epizootiology of disease. Needless to say, the groups found difficulty in defining the scope of their deliberations as inevitable overlaps occurred. The symposium did however, succeed in outlining the contents of a Handbook to be called $A$ Practical Guide to the Study of Productivity of Large Herbivores which would contain some fourteen chapters dealing with individual aspects of this vast problem. It was hoped that this Handbook would be in an advanced stage of preparation by April I966 when the General Assembly of IBP took place, but the time-table lagged.

The production of this Handbook will be one positive contribution towards the study of wild herbivores but its application is quite another matter. The symposium showed clearly that field ecologists were often hampered in their work by lack of experience in nutritional or physiological methods and the contribution that could be made by those who are experienced and skilled in this kind of work with domestic herbivores was considerable. The methods that have been developed should be used, whenever possible, with wild herbivores. This, however, poses a problem. The majority of these methods can only be used on captive and tamed animals and are useful only for establishing 'base-lines' for the comparison of different species with domestic stock under strictly comparable conditions. The establishment of baselines will presumably be helpful in deciding which of the available species can be taken from their natural environment and farmed profitably, but the difficulties of interpreting such base-lines in terms of the ecosystems in which wild herbivores live may prove to be exceptionally difficult. The ability of wild herbivores to survive or multiply in their natural environments presumably will depend as much upon their habits and behaviour, their speed, their selection of food from the available herbage, their ability to find water, shelter and safety as upon their physiology, and we shall not understand these attributes except by intensive study of the ecological system.

It could be that there is little difference between the domestic and wild ruminants in their ability to digest and live upon a good meadow hay so that this kind of comparison would be a little help in deciding which species to propagate. We might go further and compare the ability of domestic and wild ruminants to digest and live upon wild herbage and here again there might be little difference between them. 
Behavioural habits combined with physiological variations are more likely to influence the result especially with ruminants that normally live in areas where there is a hard, cold winter. Seasonal variation in their metabolism and reproductive cycle may have considerable effects as, for example, in North American deer. If a study is made of the selection of herbage and browse between domestic and wild species, it would certainly show considerable differences between them and this could have considerable implications in the ability of different species to live and multiply in a given environment. A study of the selection of herbage by wild ruminants is important. It is also very difficult for no one has succeeded in doing this in a quantitative way for hill sheep that are freely grazing. Even so, a qualitative picture of the selection of herbage or browse by wild ruminants would be helpful and would in turn give useful information on the effects of fauna upon the balance of vegetation.

I hope I have said enough about this problem to show that there is practically everything to learn about it. There is a need for the physiological and nutritional study of individual captive and tamed wild herbivores in areas where laboratory facilities are close to hand and there is a need to intensify ecological field work, making use of the methods that will be available in the projected handbook.

Elands are already being farmed by one enterprising farmer in South East Africa and attention is also being given to them in the USSR. One object of this programme could be to see whether it was more productive to select and farm indigenous species rather than to introduce European strains of domestic ruminants. There is a matter that seems to cause strong feelings. As a generalization, it seems probable that the capabilities for survival of indigenous species would be higher than that of introduced domestic stock, especially when conditions are harsh. In addition, indigenous stock may be expected to have greater resistance to endemic infectious diseases than introduced stock. On the other hand, when conditions are good, the probability is that domestic stock which have been selected for generations for high production should be more profitable than indigenous stock. There seems no reason why an answer should not be found to these propositions.

The more difficult proposition of using existing ecological systems with controlled culling, raises the problem of ways and means of transporting carcasses from the bush to cold storage. In hot countries this is probably the greatest impediment to using 'game' meat for human consumption in an acceptable and economic way. It is this aspect of the problem that raises considerable doubt whether the use of existing ecosystems can ever become a practical proposition unless there is large expenditure in providing refrigerated transport and collecting stations.

Turning now to the IBP at present in operation in the United Kingdom, we find that many projects are directed towards making better use of poor land. Much of this work is not under UM as such, but the scope of the work is so closely related to the herbivore project that it should be mentioned here.

Sections PT and CT include studies of secondary productivity by sheep on the Moor House National Reserve. This is being carried out by the staff of the Nature Conservancy with advice from the Hill Farming Research Organization. A similar project is being carried out on Snowdownia and a study of cattle on two of the Nature 
Conservancy stations are concerned with shrub clearance. The Nature Conservancy also is concerned with a study of the population of red deer on the Island of Rhum. The study of the Soay sheep population of Hirta and St Kilda is included as an IBP project and is under the care of Drs P. A. Jewell and D. J. Martin. These projects are similar to the African project and could be of direct value to the country if they stimulated interest in improved use of poor land. It should not be overlooked that there are about 17 million acres classified as rough grazing in England, Wales and Scotland in comparison to 18 million acres of arable land and $\mathrm{I} 3$ million acres of permanent grass; i.e. a little over one-third of the acres of this country are poor, rough grazing.

These figures in themselves show that greater attention to the use of such land for stock rearing of either domestic or wild species would make a substantial difference to the ability of this country to provide our own animal protein supply. The Department of Agriculture for Scotland does support a Hill Farming Research Organization and this organization is in a position to examine the full possibilities of hill stock farming. There is however no fixed base-line against which they can work, as profitability in agriculture can be altered by subsidies and changes in government policy. IBP can study the use of poor grazings, purely in a biological way, indeed, I suppose we can say that it is concerned with long-term biological economics rather than immediate financial gains.

Section UM has one project under its wing in this country which is directly related to wild herbivore project. Dr P. N. Hobson of the Rowett Research Institute has undertaken a study of the microflora and fauna of the rumen of the red deer on the Scottish hills. This project is one that is very suitable for IBP; it bears on the often expressed thought that wild ruminants may harbour cellulolytic bacteria that are more active or more numerous than the strains commonly found in domestic stock. This has been suggested in relation to the African wild ruminants. Nobody has ever produced any satisfactory evidence that this is so. If there is any appreciable difference between different species of ruminants in their abilities to digest herbage, it could be due to differences in the periods which the food remains in the various parts of the stomach or gut; for example, both the kangaroo and the hippopotamus eat, for their weight, large quantities of herbage but the passage of food residues through the gut is rapid and the extent to which food is digested is less than in the ruminant. Time is an important factor in determining the extent of digestion of fodders and a rapid passage mitigates against efficient digestion and a slow passage increases the extent of digestion. Neither the kangaroo nor the hippo have the same kind of complicated stomach as the ruminant; but their gastric anatomies are similar to each other.

Large herbivores are not always terrestrial animals. Mr Pirie has frequently drawn attention to the fact that the Syrenia live on water plants and are estuarine animals that are in danger of extinction. He points out the useful purpose they serve in keeping waterways clear of weeds and that they are locally used as sources of meat. In view of these two attributes, he suggests they should receive study with the view 
of preserving them as a species and making use of their properties. This is a project that could well become part of the IBP.

Many of the projects of Section UM that are related to human nutrition are equally related to animal nutrition. For example, the work of determining the value of different sources of plant proteins is usually done on chicks or rats and the results are directly applicable to feeding poultry and probably pigs as well.

There is a need to study high altitude animals such as the alpacca which in South America is an important domestic animal. There is as much need to study the effects of deprivation of food especially in wild ruminants as this is a customary seasonal effect. Physiological adaptations to meet the stresses of food deprivation in a hard winter and alternatives to lay down body stores during the summer would be an interesting physiological study in itself. Study of extremes often reveals principles that may be overlooked in studying animals maintained under equitable conditions. IBP can do much to assist work of this nature, not only by drawing attention to the problems but also by supporting new projects or adding support to existing work that could, with advantage, be expanded. It is probable that in expansion of existing projects which do not normally command much support from governmental or other bodies IBP can best serve its purpose. 